\title{
Morphological Change in Seabed Surrounding Jinwoo-Island Due to Construction of New Busan Port - Qualitative Evaluation through Numerical Simulation
}

\author{
Namseeg Hong $\oplus^{*}$ \\ *Department of Civil Engineering, Donga University, Busan, Korea

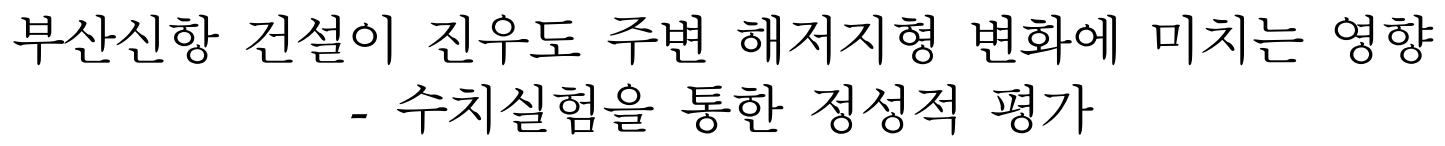 \\ 홍남식(10* \\ *동아대학교 토목공학과
}

KEY WORDS: Busan new port 부산신항, Nakdong river estuary dam 낙동강 하구둑, Morphological change of seabed 해저지형 변화, Qualitative Evaluation 정성적 평가

\begin{abstract}
In this study, a qualitative evaluation of the morphological changes in the seabed surrounding Jinwoo-Island due to the construction of the new Busan port were determined through a numerical simulation. Various scenarios for the discharge of the Nakdong river estuary dam and construction stage of the new Busan port were established and utilized for an indirect and qualitative investigation through simulation using the numerical model implemented in this study. It was concluded through a qualitative study that the morphological changes in the seabed surrounding Jinwoo-Island were typical estuary seabed changes due to the discharge of the Nakdong river estuary dam and waves from the open sea. The effects from the construction of the new Busan port were relatively small.
\end{abstract}

\section{1. 서 론}

낙동강 하구 울타리섬 주변해역의 지형변화는 수리역학적 환 경(하구둑 방류, 조석, 파랑 등)에 의하여 활발하게 진행되어 왔 으며 여러 연구(Kim and Ha, 2001; Kim at al., 2005; Jang and Kim, 2006; Oh et al., 2010; Jeon et al., 2010)에서 확인되었다. 낙동강 하구 울타리섬의 지형변화에 영향을 미치는 인자 중 낙 동강 하구둑 방류는 인위적인 요인으로 분류된다. 즉, 하계 태 풍이후 토사농도가 큰 인위적인 대량 방류수와 함께 하구둑 외 해로 이송된 토사가 하구둑 인근에 퇴적되고, 다시 외해파랑 및 조류에 의하여 이송되어 울타리섬 주변지역의 지형변화에 영향 을 미치게 되는 역학적 특성을 확인하였다(Kim and Hong, 2008).

부산항 신항만 건설은 자연 상태의 지형을 변화시키기 때문 에 이로 인한 수리역학적 환경 변화(흐름의 양상과 크기, 파고 등)가 불가피하게 발생된다. 이러한 수리역학적인 변동은 퇴적
물의 이동현상을 통하여 기존의 평형을 이루던 자연지형 및 저 질 상태로부터 새로운 평형 상태를 이루게 하는 원인이 된다. 따라서 신항만 건설로 인하여 인근 해역인 낙동강 하구 울타리 섬 영역에서 국지적인 침식 또는 퇴적 현상이 예상된다.

부산항 신항만 건설 이후 진우도 협수로의 지형변화로 소형 선박의 항행에 불편을 겪었다는 민원이 꾸준히 현재까지 제기 되어 오고 있다. Yonn et al.(2005)은 진우도 주변의 단기간(3개 월)의 퇴적환경 변화를 진우도 주변 해안선 변화를 통하여 확인 하였으며, Kim et al.(2008)은 2008년 지형(낙동강 하구둑부터 부 산신항을 포함하는 영역)을 적용하여 연간 진우도 주변의 지형 변화를 수치시뮬레이션을 통하여 조사하였으며, 협수로의 지형 변화 양상을 확인하였다.

진우도를 포함한 낙동강 하구지역은 장기 및 단기적인 지형 변화 폭이 큰 지역으로, 장기지형변화를 정량적으로 정확하게 평가하기 위해서는 정확하고 다양한 입력 자료, 즉 조사 과업기 간 내의 수심 분포 및 변화, 과업대상해역의 외력인 바람, 파랑

Received 14 February 2018, revised 31 May 2018, accepted 7 June 2018

Corresponding author Namseeg Hong: +82-10-2585-0817, hns0817@dau.ac.kr ORCID : https://orcid.org/0000-0002-1589-2617

(c) 2018, The Korean Society of Ocean Engineers

This is an open access article distributed under the terms of the creative commons attribution non-commercial license (http://creativecommons.org/licenses/by-nc/3.0) which permits unrestricted non-commercial use, distribution, and reproduction in any medium, provided the original work is properly cited. 
(평상시, 이상시), 조류 이외에도 해저질의 분포 및 물리적 특성, 지층분포 및 최상층두께, 낙동강으로부터 유입되는 유량, 토사 성분 및 농도의 시계열자료 등이 필요하다. 그러나 충분한 자료 확보가 이루어지지 않은 상태로 정확한 정량적 평가는 무리라 판단하여 Hong(2010a)은 정성적 평가를 실시한 바 있다. 즉, 부 산항 신항의 건설로 인해 발생하는 조석 및 파랑에 의한 흐름 장(해저토사의 이송외력)의 변화로 인한 지형변화 차이만을 평 가한 것으로서, 대상해역을 진우도 주변에 한정하였으며, 미비 자료는 경험치나 주변자료로부터 유추, 적용하여 가능한 한 실 제적인 장기지형 변화를 나타내고자 하였다. 즉, 부산항 신항 건설 전과 2008년의 수심도에 각각 동일한 인자, 즉 동일한 파 랑 및 조류, 동일한 해저질 분포 및 물리적 특성, 동일한 지층의 최상층 두께 및 지질, 동일한 유입유량, 토사성분 및 농도자료 를 적용하여 각각 1 년간의 지형변화를 시뮬레이션하였으며, 진 우도 인근해역의 지형변화는 신항 건설로 인한 조류 등의 흐름 변화에 기인했다기보다는 외해파랑에 의해 발생하는 과정 중에 있는 것으로서, 전형적인 외해파랑에 의한 지형변화 중에 있는 것으로 판단하였다

상기의 정성적 평가의 문제는 진우도 주변 협수로 지형변화 의 주된 원인이 외해파랑이라는 것을 추론한 것으로서, 이미 기 술하였듯이 부산항 신항 건설 전과 2008년의 수심도에 동일한 해양환경을 적용한 것으로 10 여년에 걸친 부산항 신항 건설기 간을 고려하지 않았다. 그러므로, 본 연구의 목적은 건설 이전 부터 2016년까지의 단계별 수심자료를 최대한 적용하여 부산항 신항 건설 단계별로 진우도 주변해역의 지형변화를 정성적으로 좀 더 정확하게 조사하였으며, 여러 영향 인자 중 낙동강 하구 둑 방류 영향과의 상대적 비교를 위하여 방류유무에 따른 영향 도 조사하였다.

\section{2. 모델 개요}

본 연구의 모델은 Hong et al.(2008)에 의해 개발된 해수유동 모델, Hong(2010b)에 의해 개발된 이류- 확산 및 퇴적물 이송 모델에 파랑모델인 SWAN(Simulating waves nearshore)에 적용된 근해풍파 모델을 결합한 것이다.

\section{1 해수 유동}

해수유동 모델은 수심평균된 2차원 비선형 지배방정식을 2 차항 정밀도를 가진 음해 $\mathrm{ADI}$ 유한차분법(Implicit $\mathrm{ADI}$ finite difference scheme of second order accuracy)을 이용하여 계산하 여, 해수유동 현상을 재현하는 모델이다. 지배방정식은 식(1)-(3) 과 같다.

$$
\frac{\partial \zeta}{\partial t}+\frac{\partial p}{\partial x}+\frac{\partial q}{\partial y}
$$

$$
\begin{aligned}
& \frac{\partial p}{\partial t}+\frac{\partial}{\partial x}\left(\frac{p^{2}}{h}\right)+\frac{\partial}{\partial x}\left(\frac{p q}{h}\right)+g h \frac{\partial \zeta}{\partial x}+\frac{g p \sqrt{p^{2}+q^{2}}}{C^{2} \cdot h^{2}} \\
& -\frac{1}{\rho_{\omega}}\left[\frac{\partial}{\partial x}\left(h \tau_{x x}\right)+\frac{\partial}{\partial x}\left(h \tau_{x y}\right)\right]-\Omega q-f V V_{x}+\frac{h}{\rho_{\omega}} \frac{\partial}{\partial x}\left(P_{a}\right)=0
\end{aligned}
$$

$$
\begin{aligned}
& \frac{\partial q}{\partial t}+\frac{\partial}{\partial y}\left(\frac{q^{2}}{h}\right)+\frac{\partial}{\partial x}\left(\frac{p q}{h}\right)+g h \frac{\partial \zeta}{\partial y}+\frac{g q \sqrt{p^{2}+q^{2}}}{C^{2} \cdot h^{2}} \\
& -\frac{1}{\rho_{\omega}}\left[\frac{\partial}{\partial y}\left(h \tau_{y y}\right)+\frac{\partial}{\partial x}\left(h \tau_{x y}\right)\right]-\Omega p-f V V_{y}+\frac{h}{\rho_{\omega}} \frac{\partial}{\partial x}\left(P_{a}\right)=0
\end{aligned}
$$

상기식에서,

$h(x, y, t):$ 수심 $[\mathrm{m}]$

$\zeta(x, y, t)$ : 해수면변화 [m]

$p, q(x, y, t):\left[\mathrm{m}^{3} / \mathrm{s} / \mathrm{m}\right]=\left(u_{h}, v_{h}\right)$ 방향 유량

$(u, v)=$ 수심평균된 $x$ 와 $y$ 방향 유속

$C(x, y):$ chezy저항계수 $\left[\mathrm{m}^{1 / 2} / \mathrm{s}\right]$

$C=\mathrm{M} \cdot \mathrm{h}^{1 / 6} \quad M:$ Manning No.

$g$ : 중력가속도 $\left[\mathrm{m} / \mathrm{s}^{2}\right]$

$f(v)$ : Wind 마찰계수

$V, V_{x}, V_{y}(x, y, t): x, y$ 풍속성분 $[\mathrm{m} / \mathrm{s}]$

$\Omega(x, y)$ : Coriolis parameter (s-1)

$P_{a}(x, y, t)$ : 대기압 $\left[\mathrm{kg} / \mathrm{m} / \mathrm{s}^{2]}\right.$

$\rho_{\omega}:$ Density of water $\left[\mathrm{kg} / \mathrm{m}^{3}\right]$

$\tau_{x x}, \tau_{x y}, \tau_{y y}:$ 유효전단응력 성분

\section{2 이류 확산 및 퇴적물 이송}

상기의 유동모델에 추가하여 용해되어 있거나 부유되어 있는 물질의 이류 및 확산을 예측하기 위하여 다음의 식 (4)와 같은 이류-확산식을 지배방정식으로 한다. 여기서, 식 (4)는 물질의 이류항과 확산항 뿐만 아니라, 물질의 용출 및 흡입에 대한 항 또한 포함하고 있다.

$$
\begin{aligned}
& \frac{\partial}{\partial t}(h C)+\frac{\partial}{\partial x}(u h C)+\frac{\partial}{\partial y}(v h C)+\frac{\partial}{\partial z}(w h C) \\
& =\frac{\partial}{\partial x}\left(h D_{x} \frac{\partial C}{\partial x}\right)+\left(h D_{y} \frac{\partial C}{\partial y}\right)+\left(h D_{z} \frac{\partial C}{\partial z}\right)-F h C+S
\end{aligned}
$$

여기서, $C$ : 혼합농도

$$
\begin{aligned}
& u, v, w,: x, y, z \text { 방향 속도 성분 }[\mathrm{m} / \mathrm{s}] \\
& h: \text { 수심 }[\mathrm{m}] \\
& D_{x}, D_{y}, D_{z}: x, y, z \text { 방향에서 확산계수 }\left[\mathrm{m}^{2} / \mathrm{s}\right] \\
& F: \text { 선형감소계수 }[1 / \mathrm{s}] \\
& S: Q_{s}\left(C_{s}-C\right) \\
& Q_{s}: \text { 용출 또는 용입량 }\left[\mathrm{m}^{3} / \mathrm{s} / \mathrm{m}^{2}\right] \\
& C_{s}: \text { 용출 또는 용입 유량에서의 혼합농도 }
\end{aligned}
$$

위의 식 (4)에서 $u$ 와 $v, w$ 는 각각 $x, y$ 및 $z$ 방향으로의 유속으 로 유동결과로부터 그 값을 얻는다. 확산계수 $D_{x}, D_{y}, D_{z}$ 등은 등방난류확산과 수심평균화에 따른 분산을 포함한다.

식 (4)를 수치해석적으로 풀어내기 위하여 3차 양해유한차분 법인 Ultimate 방식(Leonard, 1991)을 사용하였다. 이 수치해석 기법은 Quickest 방법으로부터 변형된 것으로 오염물질의 이동 및 확산을 예측하는 데 많이 사용된다.

비점착성 퇴적물의 침강속도는 Van Rijn(1993)의 방법에 따라 계산된다. 즉, 부유물 또는 퇴적물의 직경에 따라 식 (5)-(7)이 적용된다. 


$$
\begin{aligned}
& \mathrm{w}_{s, 0}^{(\ell)}=\frac{\left(s^{(\ell)}-1\right) g d_{s}^{(\ell) 2}}{18 v}, \quad 65 \mu m<d_{s} \leq 100 \mu m \\
& \mathrm{w}_{s, 0}^{(\ell)}=\frac{10 \nu}{d_{s}}\left[\left(1+\frac{0.01\left(s^{(\ell)}-1\right) g d_{s}^{(\ell) 3}}{v^{2}}\right)^{0.5}-1\right] \\
& \mathrm{w}_{s, 0}^{(\ell)}=100 \mu m<d_{s} \leq 1000 \mu m \\
&
\end{aligned}
$$

상기 식에서,

$s^{(\ell)}$ 퇴적물 $(\ell)$ 상대밀도 $\rho_{s}^{(\ell)} / \rho_{\mathrm{w}}$

$d_{s}^{(\ell)}$ 퇴적물 직경 $(\ell)$

$v$ 물의 동점성계수 $\left[\mathrm{m}^{2} / \mathrm{s}\right]$

소류사량의 이송크기와 방향을 포함하기 위한 시뮬레이션을 위 하여 Van Rijn(1993)이 개발한 근사법이 적용되어진다(식 (8)-(11)).

$$
\left|S_{b}\right|=0.006 \rho_{s} \mathrm{w}_{s} d_{50}^{(\ell)} M^{0.5} M_{e}^{0.7}
$$

여기서, $S_{b}=$ 소류사량 $[\mathrm{kg} / \mathrm{m} / \mathrm{s}]$

$M=$ Wave와 Current에 의한 퇴적물 유동수 $M_{e}=$ 초과된 퇴적물 유동수

$$
\begin{aligned}
& M=\frac{\nu_{e f f}^{2}}{(s-1) g d_{50}} \\
& M_{e}=\frac{\left(\nu_{e f f}-\nu_{c r}\right)^{2}}{(s-1) g d_{50}} \\
& \nu_{e f f}=\sqrt{\nu_{R}^{2}+U_{o n}^{2}}
\end{aligned}
$$

여기서, $\nu_{c r}$ 는 초기운동을 위한 한계수심평균속도 $(\mathrm{m} / \mathrm{s})$ 이며, $\nu_{R}$ 은 같은 수심평균속도의 크기로 바닥층에 속도 또는 가상로그 속도 분포로 부터 계산된다.

\section{3 근해 풍파 파랑}

본 연구에서 적용한 근해 풍파 모델은 네덜란드에서 개발되 어 공개된 SWAN으로 근해지역에서 단주기 Short crested 파랑 들의 전파, 생성과 소멸을 산정하는 모델이다. 이 모델은 수심 변화에 의한 굴절과 천수 효과, 그리고 바닥마찰과 파랑의 붕괴 에 인한 에너지 분산을 포함한다. 또한 이 모델은 파랑과 해류 의 상호작용에 의한 효과도 포함하고 고정된, 매개변수의 방향 이 분리된 모델이다. 해류의 영향을 참조하기 위해서, 이 모델 에서의 기본 방정식들은 스펙트럼 파동 밀도에 관한 보존방정 식을 사용한다. 보존방정식의 매개변수화는 독립변수로서 파동 스펙트럼의 영번째와 첫번째 모멘트를 사용함으로써 얻어진다. 이것은 다음과 같은 두 개의 편미분 방정식으로 식(12)-(13)과 같다.

$$
\frac{\partial\left(c_{g x} m_{0}\right)}{\partial x}+\frac{\partial\left(c_{g y} m_{0}\right)}{\partial y}+\frac{\partial\left(c_{\theta} m_{0}\right)}{\partial \theta}=T_{0}
$$

$$
\frac{\partial\left(c_{g x} m_{1}\right)}{\partial x}+\frac{\partial\left(c_{g y} m_{1}\right)}{\partial y}+\frac{\partial\left(c_{\theta} m_{1}\right)}{\partial \theta}=T_{1}
$$

여기서, $m_{0}(x, y, \theta)$ : 파랑작용 스펙트럼의 0 차 모멘트 $m_{1}(x, y, \theta)$ : 파랑작용 스펙트럼의 1 차 모멘트 $c_{g x}$ 와 $c_{g y}$ : 각각 군속도 $c_{g}$ 의 $x, y$ 방향의 성분들 $c_{\theta}: \theta$ 방향의 전파속도 $x$ 와 $y$ : 직교 좌표계 $\theta$ : 파랑전파의 방향 $T_{0}$ 와 $T_{1}$ : Source

모멘트 $m_{n}(\theta)$ 는 다음과 같다.

$$
m_{n}(\theta)=\int_{0}^{\infty} \omega^{n} A(\omega, \theta) d \omega
$$

여기서, $\omega$ 는 절대 주파수이고 $A$ 는 스펙트럼 파장 작용 밀도이 다. 전파속도 $c_{g x}, c_{g y}$ 와 $c_{\theta}$ 는 선형파 이론에 사용하여 구해진다. 기본방정식의 좌측항은 굴절과 천수 효과를 고려한 것이다. $T_{0}$ 와 $T_{1}$ 은 바닥마찰과 쇄파에 기인한 국부적인 바람의 발생과 에 너지 손실을 고려한 것이다. 이런 현상들에 대한 흐름의 영향들 도 내포되어 있다.

기본방정식들은 Eulerian 유한차분법을 이용함으로써 풀며 파 동 스펙트럼의 영 번째와 첫 번째 모멘트는 다수의 분리된 방 향들에 대한 사각형의 격자에서 계산되어진다. Once- through marching procedure는 파랑전파의 주된 방향에 대해 적용한다. 모델로부터 유의파고, 평균파주기, 평균파향, 방향표준편차, 잉 여응력과 같은 적분된 파랑 매개변수가 얻어지며 방향을 가진 파랑에너지의 분산 형태의 스펙트럼 출력 데이터도 얻을 수도 있다.

\section{3. 정성적 평가 비교 방안 수립}

부산항 신항 건설 단계별 진우도 주변 지형변화 및 낙동강 하 구둑 방류 영향과의 상대적 비교를 위하여 정성적 평가방안을 수립하였다.

우선, 부산항 신항 건설 단계별에 따는 진우도 주변 지형변화 에 미치는 영향을 조사하기 위하여 주된 인자를 건설 이전부터

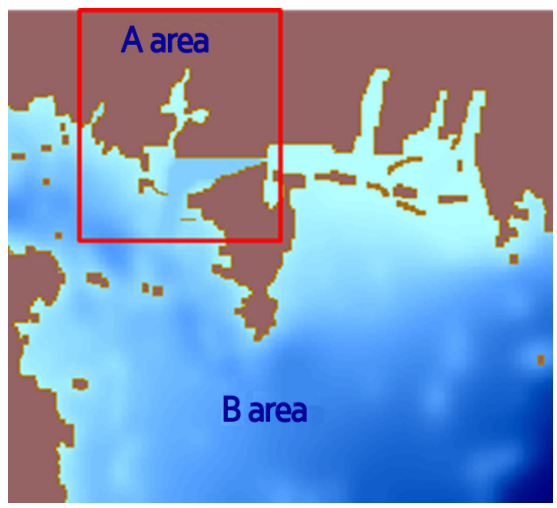

Fig. 1 Area for this study 
Table 1 Five main stage for construction of Busan New Port

Before constructi-on
During constructi-on of
Dumping area of dredged
soil and north dock

2016년까지의 단계별 수심자료로 보았다. 그러나 확보할 수 있 는 단계별 수심자료는 Fig. 1에 나타낸 A영역에 한정되어 있으 므로 $\mathrm{B}$ 영역의 해저지형은 일정 시점(신항 건설 전)에서의 수심 으로 고정하고 $\mathrm{A}$ 영역의 해저지형 변화만 반영하여 시뮬레이션 을 수행하였다. A영역의 해저 지형은 Table 1 의 주요 5 단계를 고려(신항 건설 전, 투기장 조성, 북컨 조성, 준설 단계, 현상태) 하며, 외해 파랑 및 조류 조건, 홍수기 하천 유입 토사 및 공사 중 부유토사는 가능한 한 많은 자료를 확보하여 각 단계별로 동일한 입력 자료를 사용하였다. 장기 지형변화 시뮬레이션을 수행한 후, 각 단계별 진우도 주변 해저지형의 침 - 퇴적 특성을 정량적으로 상대 비교함으로써 부산항 신항 건설이 진우도 주 변 협수로 지형에 미치는 영향을 검토하고자 하였다.

앞서 언급한 동일한 모델을 적용하여 하구둑 방류만을 제거

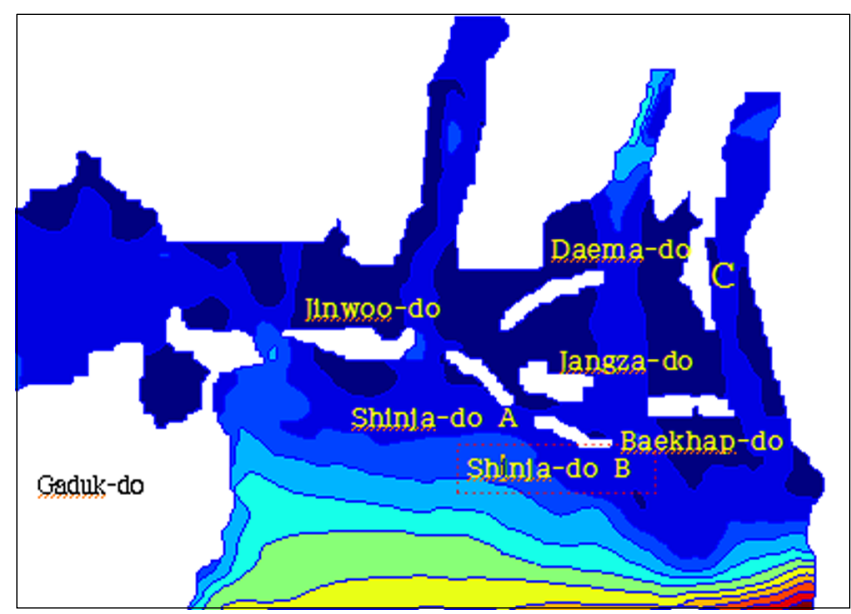

(a) Bathemetry before the construction of Busan New Port

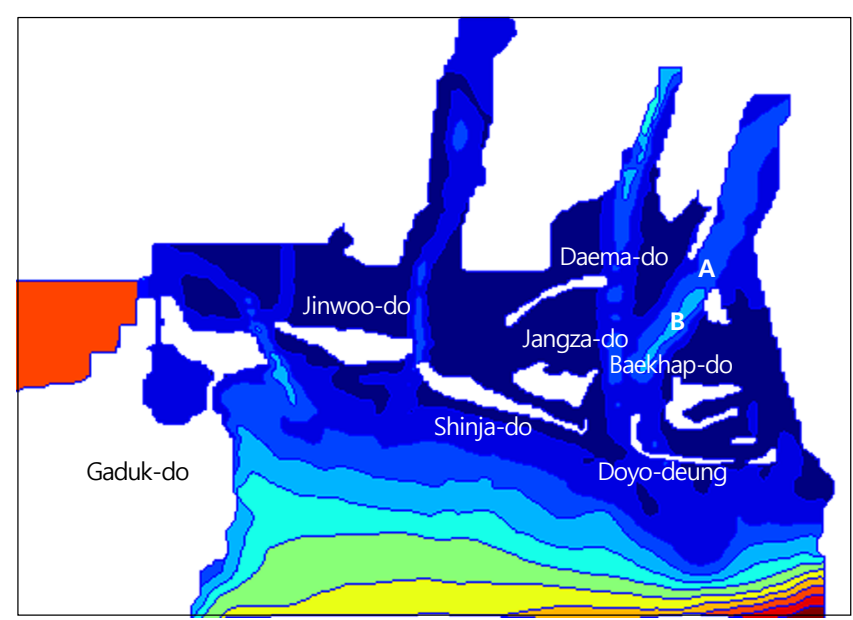

(b) Bathemetry of 2008

Fig. 2 Bathemetry before the construction of Busan New Port and 2008

하고 수행한 결과와 하구둑 방류를 포함하여 얻은 결과를 정량 적으로 상대 비교함으로써 하구둑 방류의 영향도 조사하였다. 이 경우에는 부산항 신항 건설 전의 수심도는 1980년 발행 해 도를 기준으로 수립하였고, 2008년 수심도는 2006년 발행 수치 해도를 기본으로 2008 년까지의 변화를 반영하여 수립한 것으로 그림 Fig. 2에 나타내었다. Fig. 2(a)와 Fig. 2(b)를 비교하면 낙동 강 하구지역의 지형변화가 활발히 일어나고 있음을 알 수 있다. 즉, 그림의 눌차만 해역은 부산항 신항 건설로 인해 협수로 폭 이 급격히 감소하였으며, 진우도는 북동쪽 일부 해안 형상이 변 하며 외해방향으로 진우도 전체가 전진하는 양상을 보여준다. 또한, 신자도 $\mathrm{A}, \mathrm{B}$ 구역은 병합되어 신자도가 하나의 섬으로 이 어지며 장자도, 대마등 및 백합등은 형상 및 크기가 변하고, 백 합등 남쪽에 도요등이 새로 생성된다.

이외에도, 주목할 만한 현상으로 Fig. 2(a)의 낙동강 하구둑 근처 C구역의 모래톱이 Fig. 2(b)에서 보듯이 A와 B구역으로 분 리되어 지류를 형성하게 되어 낙동강 하구 주변의 하구둑 방류 에 의한 유속장이 건설 전에 비하여 차이가 나게 됨을 추측할 수 있다. 


\section{4. 수치모델 수립 및 시뮬레이션 시나리오 작성}

\section{1 모델 영역, 격자체계 및 외해 경계조건}

Table 2에서 보듯이 파랑의 경우 세부역에 3 가지 종류의 Dynamic nesting 격자시스템을, 조석의 경우 3 가지 종류의 Dynamic nesting 격자시스템을 적용하되, 각 격자시스템간의 자료교환은 자동경계 전이 방식(Dynamic nesting method)을 적용하여 시뮬레이션 시간을 단축하고 결과의 정확성을 증가시켰다. 이때, 자동경계전이(Dynamic nesting)는 경계에서의 유속장을 자동전이(Dynamic transfer) 할 수 있 게 하였다. 앞서 Table 2에서 기술하였듯이 Grid 간격이 일정한 Dynamic nesting 격자시스템을 사용하였으며, 외해경계조건으로 조석모델의 경우 Hong(2010a)의 광역격자체계에서 얻은 결과로부 터 산정하여 사용하였다, 즉, 조화상수를 적용하여 만든 시간이력 조위에 항류에 의한 추가조위를 합산하여 얻었다. 파랑모델의 경 우는 해양연구원의 Hinding casting 모델로 부터 Table 1의 각 시점 의 자료를 활용하여 계산한 결과를 12 시간 간격으로 선취하고, 각 지점간의 파랑조건은 보간법을 적용하여 사용하였다.

Table 2 Model area, grid system and boundary condition for wave and tide

\begin{tabular}{|c|c|c|}
\hline & Wave & Tide \\
\hline \multicolumn{3}{|l|}{ Model area } \\
\hline Dynamic & $500 \mathrm{~m} \times 500 \mathrm{~m}$ & $100 \mathrm{~m} \times 100 \mathrm{~m}$ \\
\hline nesting grid & $100 \mathrm{~m} \times 100 \mathrm{~m}$ & $50 \mathrm{~m} \times 50 \mathrm{~m}$ \\
\hline system & $\mathrm{C} \quad 25 \mathrm{~m} \times 25 \mathrm{~m}$ & $\mathrm{C} \quad 10 \mathrm{~m} \times 10 \mathrm{~m}$ \\
\hline $\begin{array}{l}\text { Boundary } \\
\text { condition }\end{array}$ & $\begin{array}{c}\text { From results from } \\
\text { KORDI }\end{array}$ & Hong (2010a) \\
\hline
\end{tabular}

\section{2 입력자료 및 시뮬레이션 시나리오}

낙동강 하구둑에서 방류되는 유량은 Fig. 3 및 Fig. 4에서 보 듯이 2015년 수자원공사 자료를 사용하여, 하구둑 방류 구간 전
체에 균일하게 방류하는 것으로 가정하였으며, 방류 $\mathrm{SS}$ 농도는 $\operatorname{Hong}(2010 \mathrm{a})$ 에서 적용했던 토사농도를 사용하였다. 이외에도 녹 산배수펌프장 및 서낙동강 지류로부터 유입되는 유량은 낙동강 하구둑 방출유량의 $10 \%$ 로 보았으며, 해저질은 신항내 점토와 실트 혼합지역으로, 이외 지역은 사토로 보았으며, 표층두께분 포는 2005년 부산신항 남컨(2-2 단계) 진우도 전면해상 지반조 사(동아지질) 자료와 $\operatorname{Hong}$ (2010a) 시뮬레이션 결과로부터 유추 하여 세부역에 대하여 Fig. 5와 같이 수정함으로써 장기지형 변 화의 지역적인 패턴을 반영하였다.

배경농도는 연결잔교 내외측 관측(2013.04-2014.02) 부유사농 도 관측치중 Fig. 6(a)에서 보듯이 $10 \mathrm{ppm} 60 \mathrm{ppm}$ 사이의 농도중

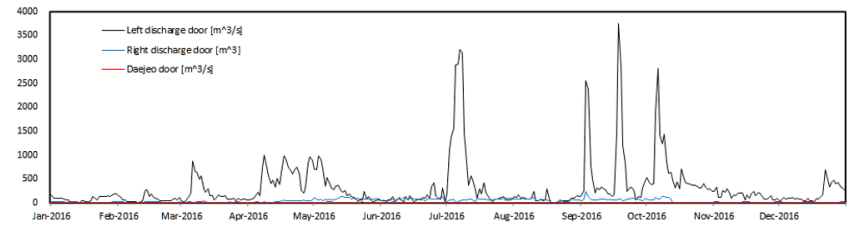

Fig. 3 Dischage from Nakdong estuary dam $\left[\mathrm{m}^{3} / \mathrm{sec}\right]$

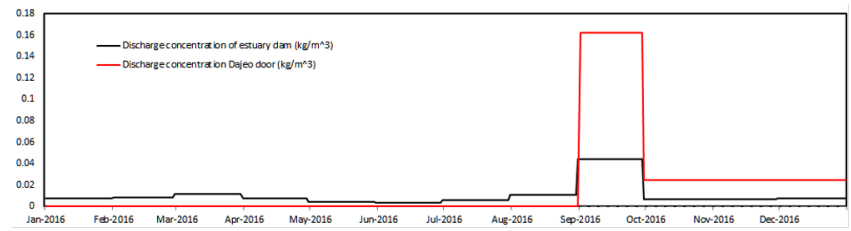

Fig. 4 SS concentration of discharge from Nakdong dam

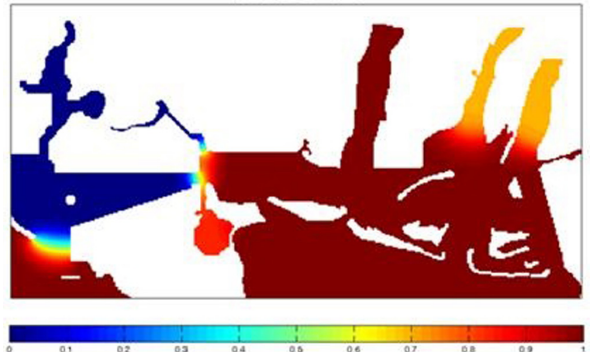

Fig. 5 Seabe thickness of nested model area B [m]

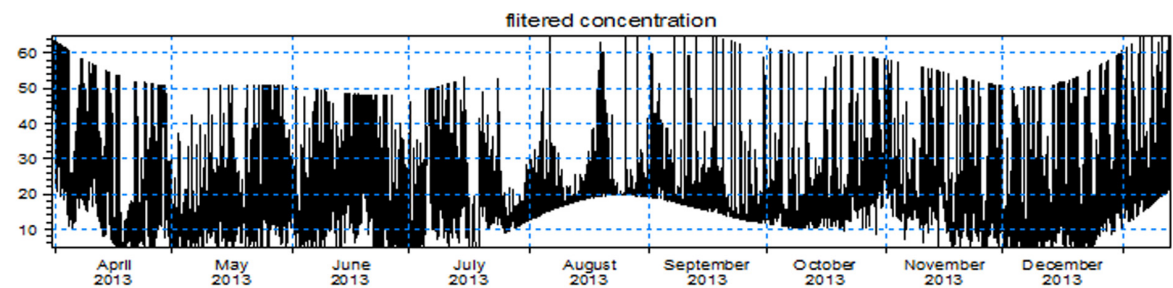

(a)

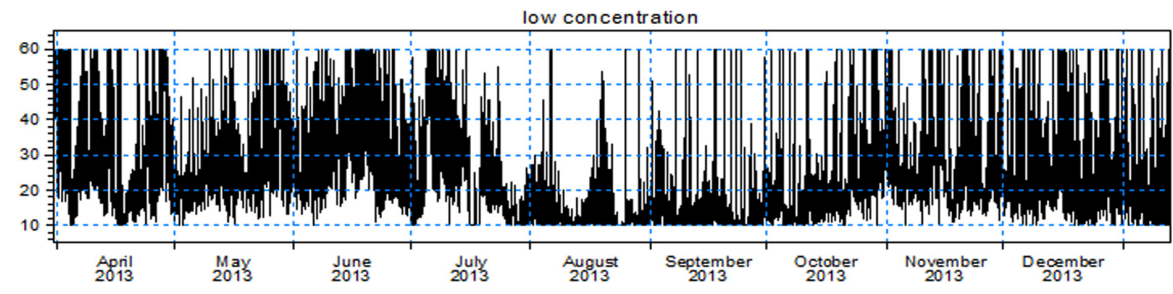

(b)

Fig. 6 Evaluation of background SS cocentration [mg/l] 
Table 3 Bathemetry and dischagrge state for simulation cases

\begin{tabular}{|c|c|c|c|c|}
\hline \multirow{2}{*}{ Simulation case \# } & \multicolumn{3}{|c|}{ Bathemetry } & \multirow{2}{*}{$\begin{array}{l}\text { Existence of discharge } \\
\text { of estuary dam }\end{array}$} \\
\hline & & Busan New Port area & Fencing island area & \\
\hline \multirow{4}{*}{$\begin{array}{l}\text { Existence of discharge } \\
\text { of estuary dam }\end{array}$} & $1-1$ & Before construction, bathemetry of 1996 & 1980 nautical chart & $\mathrm{O}$ \\
\hline & $1-2$ & 2008 construction stage & 2006 nautical chart & $\mathrm{O}$ \\
\hline & $2-1$ & Before construction, bathemetry of 1996 & 1980 nautical chart & $\mathrm{X}$ \\
\hline & $2-2$ & 2008 construction stage & 2006 nautical chart & $\mathrm{X}$ \\
\hline \multirow{5}{*}{$\begin{array}{l}\text { Construction stage of } \\
\text { Busan New port }\end{array}$} & $3-1$ & Before construction, bathemetry of 1996 & 1980 nautical chart & $\mathrm{O}$ \\
\hline & $3-2$ & Construction of North container and starting dumping area & 1980 nautical chart & $\mathrm{O}$ \\
\hline & $3-3$ & Starting dredging in port area & 1980 nautical chart & $\mathrm{O}$ \\
\hline & $3-4$ & Finishing $1^{\text {st }}$ dredging and north container area & 1980 nautical chart & $\mathrm{O}$ \\
\hline & $3-5$ & during south container & 1980 nautical chart & $\mathrm{O}$ \\
\hline
\end{tabular}

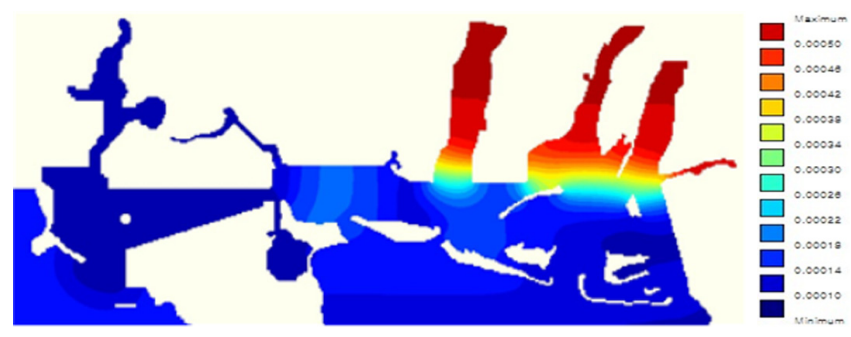

Fig. 7 Distribution of D50 grain size [mm]

$1.8 \times 10 \mathrm{e}-6$ 이상 Frequency를 제거하여 사용하였으며(Fig. 6(b)), 해저질 입경 중 D50 분포는 금번 연구에서 관측한자료 및 수자 원공사 낙동강 하구둑 인근 해저질 자료를 바탕으로 정성적 추 정하여 Fig. 7과 같이 작성하였다.

Table 3은 시뮬레이션 시나리오별 하구둑 방류유무 및 적용수 심을 나타낸 것으로, 크게 낙동강 방류 유무 및 부산항 신항 건 설 단계별로 나누어진다. 부산항 신항 건설 단계별의 경우는 전 술한 부산항 신항 영역(Table 2의 A영역)의 지형 변화에 따른 B 영역의 1 년간의 지형 반응을 조사하였다.

하구둑 방류유무의 경우는 $\operatorname{Hong}(2010 \mathrm{a})$ 이 수립하여 적용했던 모델에 하구둑 방류만을 제거하여 하구둑 방류에 의한 지형반 응만을 조사하기 위한 것으로, 부산항 신항 건설 단계별의 경우 와는 전혀 다른 입력인자를 가지고 수립된 모델이다. 즉, 주요 인자중 하구둑 방류유량 적용시기가 부산항 신항 건설 단계별 의 경우와는 관계가 없는 경우이다.

\section{5. 진우도 협수로 지형에 미치는 영향조사 및 분석}

\section{1 유속장의 변화}

부산항 신항 건설 및 낙동강 하구둑 방류가 진우도 주변 지역 의 지형변동에 미치는 유속장(파랑에 의한 유동장 포함)의 변화 를 조사하기 위하여 Fig. 8에서 보듯이 눌차만 협수로 인근 3개 지점 및 진우도-신자도 사이 중간 3 개 지점의 연간 절대평균유 속의 크기를 비교하여 Table 4에 나타내었다. Table 4에서 보듯 이 신항 건설단계에 따른 유속의 변화는 눌차만 북안 협수로 일 부 지역에서 약간 변화할 뿐 다른 정점에서는 거의 미미한 것으 로 나타났다. 그러나 낙동강 하구둑 방류유무에 따른 유속의

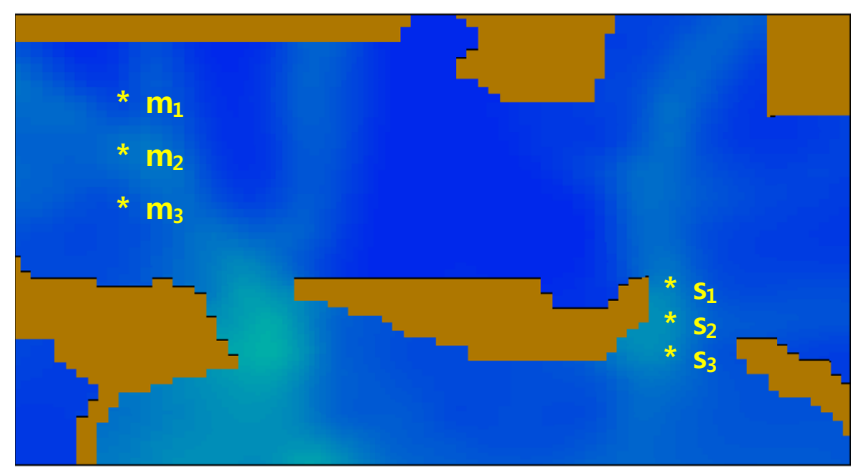

Fig. 8 Location for comparison of year-average current velocity

Table 4 Year-average current velocity at location of comparison of year-average current velocity for simulation cases

\begin{tabular}{|c|c|c|c|c|c|c|c|c|c|}
\hline & \multicolumn{5}{|c|}{$\begin{array}{l}\text { Year average current speed for } \\
\text { each construction stage } \\
{[\mathrm{m} / \mathrm{sec}]}\end{array}$} & \multicolumn{4}{|c|}{ 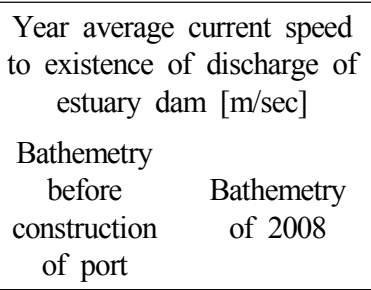 } \\
\hline & $1 \mathrm{st}$ & 2nd & 3 rd & 4 th & 5 th & with & without & with & without \\
\hline $\mathrm{m}_{1}$ & 0.01 & 0.01 & 0.02 & 0.02 & 0.01 & 0.08 & 0.09 & 0.12 & 0.13 \\
\hline $\mathrm{m}_{2}$ & 0.04 & 0.04 & 0.05 & 0.06 & 0.08 & 0.25 & 0.25 & 0.22 & 0.24 \\
\hline $\mathrm{m}_{3}$ & 0.33 & 0.34 & 0.25 & 0.27 & 0.28 & 0.25 & 0.25 & 0.15 & 0.15 \\
\hline $\mathrm{s}_{1}$ & 0.21 & 0.21 & 0.21 & 0.21 & 0.20 & 0.18 & 0.18 & 0.37 & 0.49 \\
\hline $\mathrm{S}_{2}$ & 0.20 & 0.19 & 0.20 & 0.19 & 0.19 & 0.19 & 0.19 & 0.46 & 0.58 \\
\hline $\mathrm{S}_{3}$ & 0.17 & 0.17 & 0.17 & 0.17 & 0.16 & 0.18 & 0.21 & 0.38 & 0.47 \\
\hline
\end{tabular}

변화는 신항 건설 전의 지형을 적용하였을 경우는 차이가 거의 나지 않는데 반하여 2008년 지형을 적용하였을 경우는 진우도 와 신자도 사이의 협수로 지역에서는 뚜렷하게 차이가 남을 알 수 있었다. 이유는 전술한 것처럼 낙동강 하구둑 근처 모래톱이 분리되어 지류를 형성하게 됨으로써 낙동강 하구 주변의 하구 둑 방류에 의한 유속장이 차이가 나는 것으로 판단되었다.

결론적으로, 진우도 주변해역에서의 부산항 신항 건설로 인한 
장기 유속장의 변화는 미미하며, 낙동강 하구둑 방류유무에 의 한 장기유속장의 변화 또한 울타리섬 인근 지형의 형상에 따른 지류 형성 등에 의하여 차이가 나는 것으로 판단되었다. 본 연 구에서 조사 분석한 절대 연평균 유속의 변화는 장기지형의 변 화에 미치는 영향의 정도를 단순하게 판단하는 기준으로 사용 할 수 있으나, 국부적인 장기 침 - 퇴적 양상을 나타내지는 못한 다. 그러므로 다음절에서 시뮬레이션 시나리오별 장기(연간) 침 · 퇴적 양상을 조사하였다.

\section{2 부산항 신항 건설단계별 침 · 퇴적 변화}

Fig. 9에 나타낸 A, B 및 $\mathrm{C}$ 영역에서의 부산항 신항 건설단계 별 침식 및 퇴적량을 Table 5에, 1 단계 대비 침식 및 증감비율을 Table 6에 나타내었다. 부산항 신항 건설로 인하여 건설단계가 진행될수록 대부분 퇴적이 증가하는 경향을 보이며, 그런 경향 은 $\mathrm{A}$ 영역이 가장 크게 나타나며, 다음으로 B영역, $\mathrm{C}$ 영역의 순 서로 작게 나타났다. 즉, 부산항 신항에서 멀어질수록 영향이 줄어듦을 알 수 있었다.

영역내 지역별 침 - 퇴적 양상을 조사하기 위하여 1단계 대비 침-퇴적 증감 두께분포를 Fig. 10부터 Fig. 12에 나타내었다.

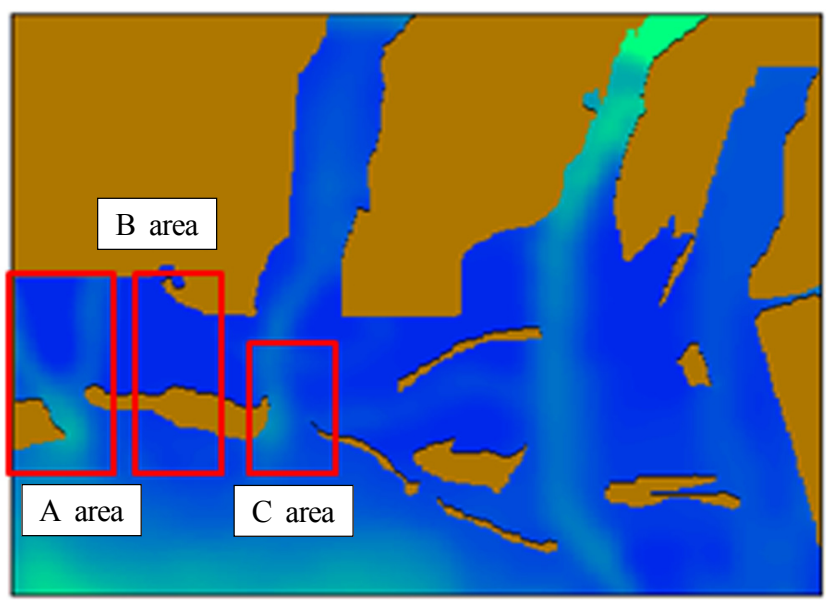

Fig. 9 Area for comparison of year-erosion and deposition

Table 5 Erosion and deposition rate for construction stage

\begin{tabular}{ccccccc}
\hline \hline Area & \multicolumn{5}{c}{ Erosion } & and deposition rate for each stage $\left[\mathrm{m}^{3}\right]$ \\
\hline \multirow{4}{*}{ A } & & $1^{\text {st }}$ & $2^{\text {nd }}$ & $3^{\text {rd }}$ & $4^{\text {th }}$ & $5^{\text {th }}$ \\
& Deposition & 70984 & 62594 & 51393 & 53893 & 47861 \\
& Erosion & -82537 & -69548 & -61740 & -60048 & -54375 \\
& Total & -11553 & -6953 & -10347 & -6155 & -6514 \\
\hline \multirow{4}{*}{ B } & & $1^{\text {st }}$ & $2^{\text {nd }}$ & $3^{\text {rd }}$ & $4^{\text {th }}$ & $5^{\text {th }}$ \\
& Deposition & 8170 & 8289 & 8466 & 9210 & 9795 \\
& Erosion & -7156 & -7202 & -7395 & -8114 & -8582 \\
& Total & 1014 & 1086 & 1071 & 1095 & 1212 \\
\hline \multirow{4}{*}{ C } & & $1^{\text {st }}$ & $2^{\text {nd }}$ & $3^{\text {rd }}$ & $4^{\text {th }}$ & $5^{\text {th }}$ \\
& Deposition & 24614 & 24981 & 24332 & 26650 & 27612 \\
& Erosion & -25232 & -25617 & -24949 & -27335 & -28322 \\
& Total & -617 & -636 & -617 & -685 & -710 \\
\hline
\end{tabular}

Table 6 Erosion and deposition rate for each construction to $1^{\text {st }}$ stage

\begin{tabular}{|c|c|c|c|c|c|}
\hline Area & Erosion $\mathrm{a}$ & depositic & percent & e to $1^{\text {st }}$ & ge [\%] \\
\hline \multirow{4}{*}{ A } & & $2^{\text {nd }}$ & $3^{\text {rd }}$ & $4^{\text {th }}$ & $5^{\text {th }}$ \\
\hline & Deposition & -11.82 & -27.60 & -24.08 & -32.57 \\
\hline & Erosion & 15.74 & 25.20 & 27.25 & 34.12 \\
\hline & Total & 39.81 & 10.44 & 46.72 & 43.62 \\
\hline \multirow{4}{*}{ B } & & $2^{\text {nd }}$ & $3^{\text {rd }}$ & $4^{\text {th }}$ & $5^{\text {th }}$ \\
\hline & Deposition & 1.45 & 3.62 & 12.72 & 19.88 \\
\hline & Erosion & -0.65 & -3.33 & -13.39 & -19.93 \\
\hline & Total & 7.13 & 5.61 & 8.00 & 19.52 \\
\hline \multirow{4}{*}{ C } & & $2^{\text {nd }}$ & $3^{\text {rd }}$ & $4^{\text {th }}$ & $5^{\text {th }}$ \\
\hline & Deposition & 1.49 & -1.15 & 8.27 & 12.18 \\
\hline & Erosion & -1.53 & 1.12 & -8.33 & -12.25 \\
\hline & Total & -2.99 & 0.05 & -10.91 & -15.01 \\
\hline
\end{tabular}

(a) $2 \mathrm{nd}$

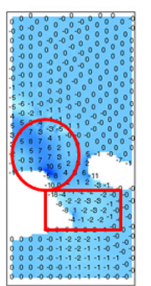

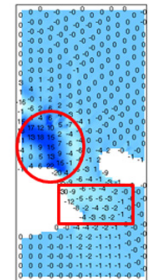

(b) 3rd

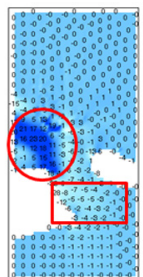

(c) 4th

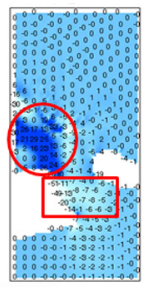

(d) 5 th
Fig. 10 Distribution of thickness of erosion and deposition for each construction stage to $1^{\text {st }}$ construction stage at $\mathrm{A}$ area

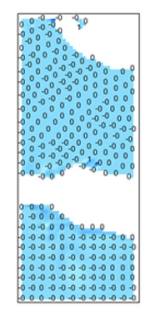

(a) $2 \mathrm{nd}$

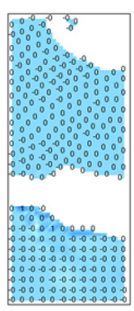

(b) 3rd

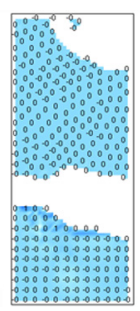

(c) 4 th

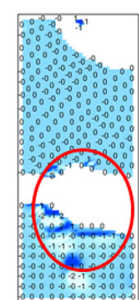

(d) 5 th
Fig. 11 Distribution of thickness of erosion and deposition for each construction stage to $1^{\text {st }}$ construction stage at $\mathrm{B}$ area

Fig. 10 는 A영역의 1 단계 대비 증감 두께분포를 각 단계(2단계부 터 5단계)별로 나타낸 것으로 $\bigcirc$ 표식 지역은 퇴적우세영역, $\square$ 표 식 영역은 침식우세영역으로 눌차만 입구 남측 해안의 협수로 지역에 주로 퇴적이 발생하는 것으로 나타났다. 반면, 눌차도와 진우도 사이는 침식이 주로 발생하며 눌차도 주변 해안에 집중 되는 경향을 띠고 있다. Fig. 11은 B영역의 1단계 대비 증감 두께 분포를 각 단계(2단계부터 5 단계)별로 나타낸 것으로 건설이 진 행됨에 따라 거의 변화가 나타나지 않다가 5 단계에 접어들어 진 우도 남측 전면 $(\bigcirc$ 표식 지역)에 약간의 지형변화가 나타났다.

Fig. 12는 $\mathrm{C}$ 영역의 1 단계 대비 증감 두께분포를 각 단계(2단 계부터 5단계)별로 나타낸 것으로 4 단계부터 5 단계에 와서 $\bigcirc$ 표식 지역에 퇴적이 집중되어 나타난다. 즉, 진우도 동측 및 신자 도 서측 끝부분에 국부적으로 퇴적이 집중되어 나타날 뿐 다른 


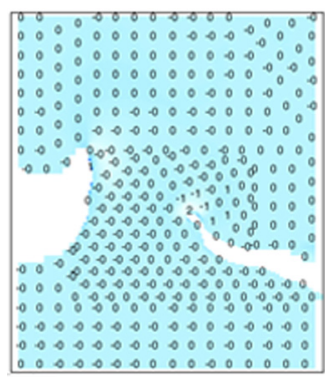

(a) $2 \mathrm{nd}$

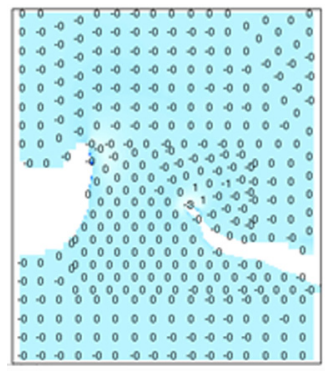

(c) 4 th

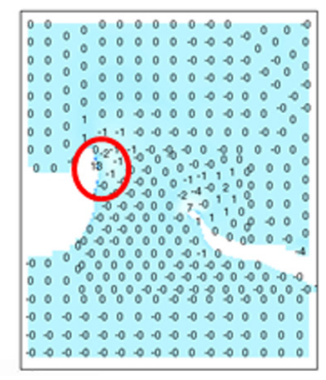

(b) 3rd

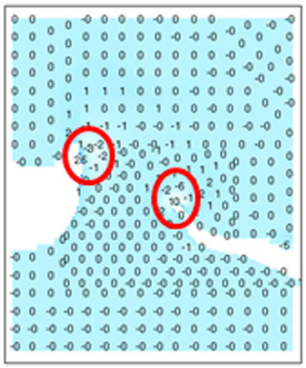

(d) 5 th
Fig. 12 Distribution of construction stage at $\mathrm{C}$ area. thickness of erosion and deposition for each construction stage to $1^{\text {st }}$

지역의 침·퇴적 양상에는 거의 변화가 없었다. 결론적으로, 부 산항 신항 건설이 진우도 주변 지형에 미치는 영향은 눌차만 인근 지역에서만 나타나며, 진우도 및 신자도 주변에서는 극히 일부분(진우도 동측 및 신자도 서측 끝 해안)에 국부적으로 나 타나는데 이는 앞 절에서 기술한 바와 같이 진우도 주변해역에 서의 부산항 신항 건설로 인한 장기 유속장의 변화는 크지 않 다는 결론과 일맥 상통하는 결과이다.

\section{3 낙동강 하구둑 방류유무에 따른 침·퇴적 변화}

낙동강 하구둑 방류유무에 따른 침 - 퇴적 변화를 조사하기 위하 여 Hong(2010a)에 수립하여 적용했던 모델 결과와 동일 모델에 하구둑 방류만을 제거하여 하구둑 방류에 의한 지형반응만을 조사 하였다. 2010년 수립된 모델의 경우 수심 및 지형은 부산항 신항 건설 전과 2008년 수심 및 지형을 적용하였으므로, 본 과업에서도 동일한 수심 및 지형에 하구둑 방류만을 제거하여 방류를 포함

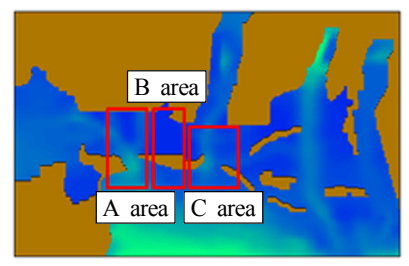

(a)

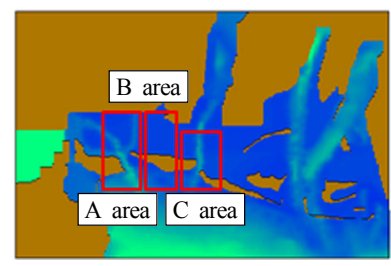

(b)
Fig. 13 Area for comparison of year-erosion and deposition; (a) before construction, (b) bathemetry of 2008

하였을 경우와 비교하였다. Fig. 13은 부산항 신항 건설 전 및 2008년 경우의 지형 및 침 · 퇴적 변화 조사를 위한 3 개 영역(A, $\mathrm{B}$ 및 $\mathrm{C}$ 영역)을 나타내었으며, $\mathrm{A}, \mathrm{B}$ 및 $\mathrm{C}$ 영역에서의 방류유무에 따른 침식 및 퇴적 변화 비교를 Table 7에 나타내었다.

Table 7에서 보듯이 신항 건설 전과 2008년의 경우 경향상 뚜 렷한 차이는 나지 않으나, 방류로 인한 영향은 $\mathrm{C}$ 영역에서 지배 적으로 나타났다. 세부영역별 방류유무에 따른 침-퇴적 특성 을 조사하기 위하여 Fig. 14부터 Fig. 16에 방류의 경우 미방류 대비 토사 증감 두께 분포도를 신항 건설 전 지형 및 2008년 지 형의 각각의 경우에 대하여 나타내었다.

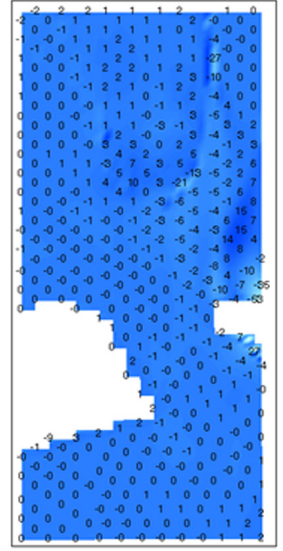

(a)

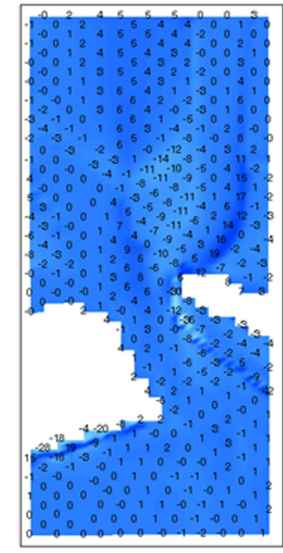

(b)
Fig. 14 Distribution of thickness of erosion and deposition due to discharge at A area.; (a) before construction, (b) bathemetry of 2008

Table 7 Comparion of erosion and deposition rate due to dischage of estuary dam

\begin{tabular}{cccccccc}
\hline \hline \multirow{2}{*}{ Area } & \multicolumn{3}{c}{ Bthemetry before construction } & \multicolumn{3}{c}{ Bathemetry of 2008 } \\
& Classification & $\begin{array}{c}\text { with } \\
{\left[\mathrm{m}^{3}\right]}\end{array}$ & $\begin{array}{c}\text { without } \\
{\left[\mathrm{m}^{3}\right]}\end{array}$ & $\begin{array}{c}\text { percent to without } \\
{[\%]}\end{array}$ & $\begin{array}{c}\text { with } \\
{\left[\mathrm{m}^{3}\right]}\end{array}$ & $\begin{array}{c}\text { without } \\
{\left[\mathrm{m}^{3}\right]}\end{array}$ & $\begin{array}{c}\text { percent to without } \\
{[\%]}\end{array}$ \\
\hline \multirow{3}{*}{$\mathrm{A}$} & deposition & 88933 & 75367 & 18 & -149738 & -118857 & -26 \\
& erosion & -109003 & -94483 & -15 & 121932 & 98969 & 23 \\
& total & -20070 & -19117 & -5 & -27806 & -19888 & -40 \\
\hline \multirow{3}{*}{$\mathrm{B}$} & deposition & 157697 & 123776 & 27 & -356189 & -320834 & -11 \\
& erosion & -349327 & -319768 & -9 & 83139 & 102268 & -19 \\
& total & -191630 & -195992 & 2 & -273050 & -218566 & -25 \\
\hline \multirow{2}{*}{$\mathrm{C}$} & deposition & 177007 & 182007 & -3 & -244214 & -201062 & -21 \\
& erosion & -560977 & -334950 & -67 & 181875 & 62566 & 191 \\
& total & -383970 & -152943 & -151 & -62339 & -138496 & 55 \\
\hline
\end{tabular}




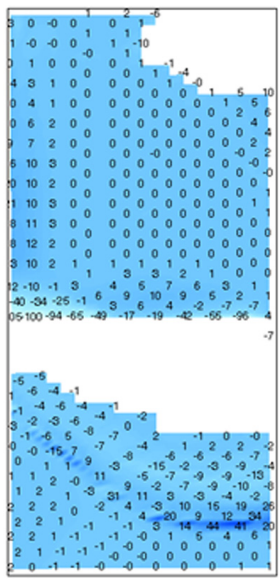

(a)

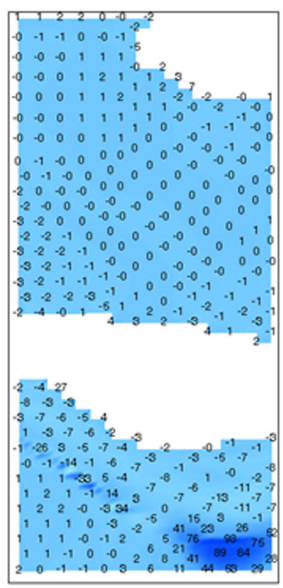

(b)
Fig. 15 Distribution of thickness of erosion and deposition due to discharge at B area; (a) before construction, (b) bathemetry of 2008

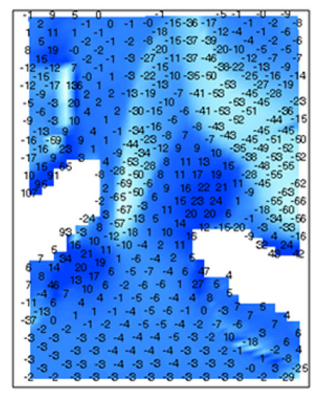

(a)

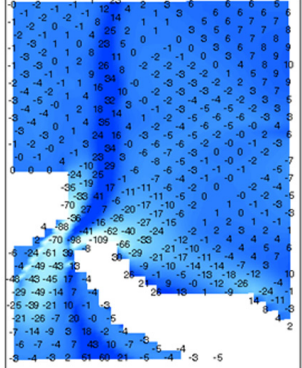

(b)
Fig. 16 Distribution of thickness of erosion and deposition due to discharge at $\mathrm{C}$ area.; (a) before construction, (b) bathemetry of 2008

$\mathrm{A}$ 영역에서는 방류로 인해 전반적으로 지형변화가 발생하 며, 특히 2008년 지형을 적용한 경우가 좀 더 크게 발생함을 알 수 있다. B영역에서도 $\mathrm{A}$ 영역과 유사한 경향을 보이며 $\mathrm{A}$ 영 역에 비하여 영향이 좀 더 증가함을 알 수 있다. 그러나 $\mathrm{C}$ 영 역에서는 방류로 인한 영향이 신항 건설 전 지형을 적용한 경우나 2008년 지형을 적용한 경우 둘 다 상당히 크게 미침 을 알 수 있으며, 신항 건설 전은 진우도와 신자도 북쪽 영역 에서, 2008년의 경우는 진우도와 신자도 사이 및 남쪽 영역 에서 방류로 인한 영향이 두드러짐을 알 수 있다.

결론적으로 낙동강 하구둑 방류로 인한 영향은 눌차만 주 변 지형에 비해 진우도와 신자도 주변지형에 지배적인 영향 을 미치며, 파랑 및 방류 등에 의한 낙동강하구 지형의 전반 적인 지형변화가 유속장의 변화를 발생하고, 이것이 방류로 인한 지형변화 양상에도 영향을 미침을 알 수 있다.

5.4 신항 건설 영향과 낙동강하구둑 방류 영향의 정성적 비교

Table 3에서 보듯이 본 과업에서 수행한 시률레이션은 (1)울타 리섬 영역은 부산항 신항 건설 전의 지형을 적용하면서 부산항 신항 영역만 건설단계별로 변화시켜 진우도 주변 지형변화를 조사하는 것과, (2)과업 전체영역을 부산항 신항 건설 전과 2008
년 지형을 적용하여 낙동강 하구둑 방류유무에 따른 진우도 주 변지형 변화를 조사하는 것으로 (1)의 경우와 (2)의 경우 시뮬레 이션의 주요 조건이 서로 다르므로 정량적 상대비교 대신 정성 적 상대비교를 통하여 신항 건설(신항 영역은 현상태, 울타리섬 영역은 신항 건설 전)로 인한 영향과 낙동강 하구둑 방류 영향 을 정성적으로 비교하였다.

Fig. 17부터 Fig. 19는 A, B 및 C영역에서 신항 건설단계별 영 향의 시률레이션 결과 중에서 1 단계 대비 5 단계 증감 분포와 하구둑 방류의 영향으로 인한 증감 분포 비교를 나타낸 것이다. Fig. 17에서 보듯이 A영역에서는 신항 건설로 인한 영향이 하구 둑방류에 의한 영향보다 우세하나, Fig. 18 의 B영역에서는 신항 건설보다 하구둑 방류의 영향이 진우도 주변 지역에 한정되어 우세하게 나타남을 알 수 있었다.

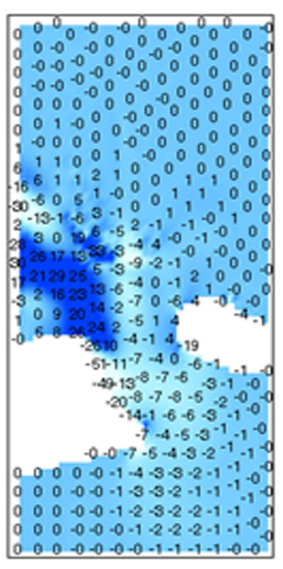

(a)

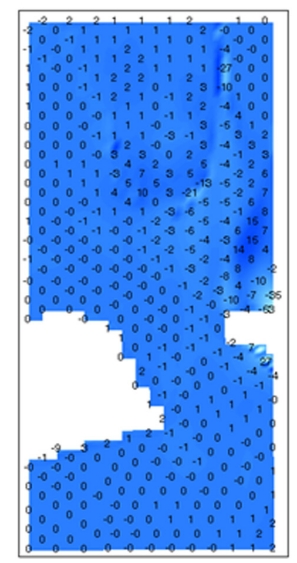

(b)
Fig. 17 Comparison at A area between effect of port construction and effect of dischage of estuary dam.; (a) Change of thickness of erosion and deposition due to port construction (b) Change of thickness of erosion and deposition due to port construction

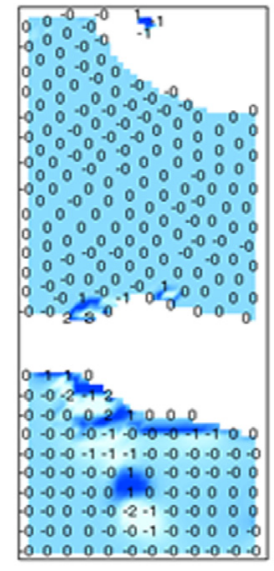

(a)

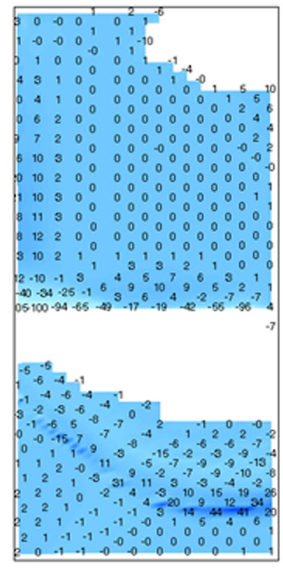

(b)
Fig. 18 Comparison at B area between effect of port construction and effect of dischage of estuary dam.; (a) Change of thickness of erosion and deposition due to port construction (b) Change of thickness of erosion and deposition due to port construction 


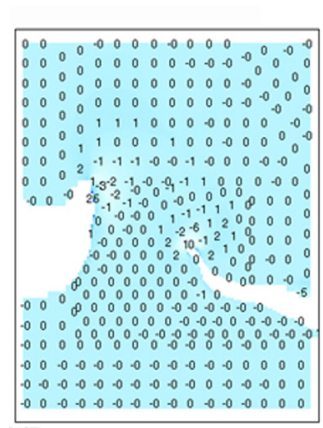

(a)

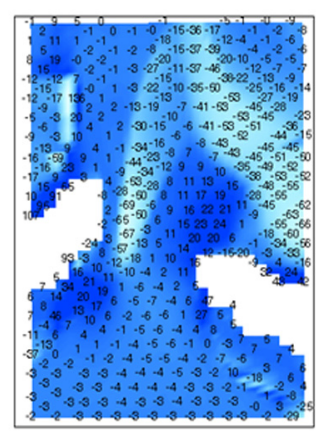

(b)
Fig. 19 Comparison at $\mathrm{C}$ area between effect of port construction and effect of dischage of estuary dam.; (a) Change of thickness of erosion and deposition due to port construction (b) Change of thickness of erosion and deposition due to port construction

이런 경향은 동진할수록 더 증가하여 Fig. 19에서 보듯이 하 구둑 방류 영향이 상대적으로 신항 건설의 영향보다 두께 분포 변화가 상당히 많이 차이남을 알 수 있다. 즉, 진우도 주변지형 의 변화에 미치는 영향은 부산항 신항 건설보다 낙동강 하구둑 방류에 의한 영향이 상대적으로 지배적이라고 판단되었다.

지금까지의 결과 분석으로부터, 진우도 주변의 지형변화는 부 산항 신항 건설로 인한 영향이 적으며, 하구지역의 방류 및 외 해파랑에 의한 전형적인 하구지역에서 발생하는 하구지형 변화 중에 있는 것으로 판단되었다.

\section{6. 결 론}

본 연구에서 부산항 신항 건설이 진우도 주변 지형에 미치는 영향을 조사하기 위하여 간접적 정성적인 검토를 위한 시나리 오 작성 및 모델을 수립하여 시뮬레이션을 수행함으로써, 하구 둑 방류유무에 따른 진우도 주변 지형 반응과 신항 건설단계별 진우도 주변 지형의 침·퇴적 양상을 상대적으로 비교하여 다 음과 같은 결론을 얻었다.

(1) 신항 건설의 영향은 눌차만 인근 지역이 영향이 크고 진 우도 주변 지역으로 동진할수록 영향이 상대적으로 적은 것 으로 나타났다.

(2) 하구둑 방류의 영향은 진우도와 신자도 주변에서 크고 서 진할수록 영향이 상대적으로 적은 것으로 나타났다.

(3) 신자도 동쪽 지형의 변화는 하구둑 방류로 인하여 발생하 며, 낙동강 울타리섬의 지속적인 지형변화로 인한 유속장의 변 화가 진우도 주변 지형의 변화를 발생시키는 것으로 판단된다. 또한, 하구둑 방류로 인한 토사공급과 이를 운반하는 파랑의 작 용도 영향을 미치는 것으로 보인다.

결론적으로, 진우도 주변의 지형변화는 부산항 신항 건설로 인한 영향이 상대적으로 적으며, 하구지역의 방류 및 외해파랑 에 의한 전형적인 하구지역에서 발생하는 하구지형 변화 중에 있는 것으로 판단되었다.

\section{References}

Kim, S.Y., Ha, J.S., 2001. Sedimentary Faces and Environmental Changes of Nakdong River Estuary and Adjacent Coastal Area. Korean Journal of Fisheries and Aquatic Sciences, 34(3), 268-278.

Kim, B.W., Kim, B.G., Lee, S.Y., 2005. Development of Mosaic Aerial Photographs for Shoreline Change Study in Nakdong Estuary. Ocean and Polar Reasearch, 27(4), 497-507.

Jang, S.T., Kim, K.C., 2006. Change of Oceanographic Environment in the Nakdong Estuary. The Sea, 11(1), 11-20.

Oh, C.Y., Park, S.Y., Choi, C.U., Jeon, S.W., 2010. Change Detection at the Nakdong Estuary Delta Using Satellite Image and GIS. Journal of the Korean Society for Geospatial Information Science, 18(1), 21-29.

Jeon, Y.H., Yoon, H.S., Lee, K.S., 2010. Spatiotemporal Variations of Coastal Sediment Transport at Barrier Islands in the Nakdong River Estuary. Journal of the Korean Society of Marine Environment and Safety, 16(2), 161-168.

Kim, K.S., Hong, N.S., 2008. The Change of Ocean around Estuary Caused by Change of Shape of Nokdong River Estuary a Sandy Plain. Proceedings of the $17^{\text {th }}$ Conference of the Korean Society of Coastal and Ocean Engineers, Mokpo, 100-103.

Kim, K.S., Hong, N.S., Chae, J.W., Lee, J.M., 2008. Morphological Simulations near Coastal Area of Jinwoo-do. Proceedings of $12^{\text {th }}$ Conference of the Korean Association of Ocean and Technology Societies, Jeju, 374-377.

Yoon, H.S., Yoo, C.I., Ryu, C. R., Lee, I.C., 2005. Sediment Environmental Change around Jinwoo-do in Nakdong River Estuary. Proceedings of Spring Conference of the Korean Society of Marine Environment and Energy, 44-49.

Hong. N.S., 2010a. The $4^{\text {th }}$ Project Report of Research and Development for Ocean Environmental Hyraulics of Busan New Port - Spreading of Suspended Sediment and Morphological Change. Busan Port Construction Office, Miinistry of Ocean and Fisheries

Hong, N.S., 2010b. Investigation of Reducing Characteristics for the Spreading of Dredging Soil and the Diffusion of Contaminant by Silt Protector Curtain through Three Dimensional Numerical Model Experiment. Journal of Ocean Engineering and Technology, 24(4), 78-85.

Hong, N.S., Kim, G.Y., Kang, Y.G., 2008. Three Dimensional Numerical Model for Flow with Silt Protector. Journal of Ocean Engineering and Technology, 22(3), 1-7.

Leonard, B.P., 1991. The Ultimate Conservative Difference Scheme Applied to Unsteady One-Dimensional Advection. Computer Methods in Applied Mechanics and Engineering, 88(1), 17-74.

Van Rijn, L.C., 1993. Principles of Sediment Transport in Rivers, Estuaries and Coastal Seas. AQUA Publications, The Netherlands. 